\title{
Fabrication of Al2024 Alloy by Core-shell Structured Ti/B4C Composite Particles
}

Eduardo Cuadros-Lugo ${ }^{1}$, Caleb Carreño-Gallardo ${ }^{2}$, Ernesto Ledezma-Sillas ${ }^{1}$, Claudia López-Meléndez ${ }^{3}$ and Jose Martin Herrera-Ramirez ${ }^{2}$

${ }^{1}$ CIMAV, Chihuahua, Chihuahua, Mexico, ${ }^{2}$ Centro de Investigacion en Materiales Avanzados S.C., Chihuahua, Chihuahua, Mexico, ${ }^{3}$ Universidad La Salle Chihuahua, Chihuahua, Chihuahua, Mexico

Particulate reinforced aluminum matrix composites (PRAMCs) have potential applications in automobile, chemical and aerospace industries due to their excellent mechanical properties such as low density, high strength and adjustable elastic modulus [1-3]. However, the addition of reinforcements (normally ceramic particles or intermetallic) in aluminum matrix decreases substantially the ductility and toughness.

Aluminum (A12024) alloy has been employed as a matrix material in $\mathrm{MMC}$ and $\mathrm{Ti} / \mathrm{B} 4 \mathrm{C}$ particles as reinforcement, both components were used as the starting materials to produce $\mathrm{Al} 2024-\mathrm{Ti} / \mathrm{B} 4 \mathrm{C}$ composites. Initial Al2024 burhs were produced by machining of $90 \% \mathrm{Ti}$ and $10 \% \mathrm{~B} 4 \mathrm{C}$ particles with a ball to powder ratio of 5:1, a high-energy mill (SPEX 8000), under an inert atmosphere of pure argon gas. The milling container was made of hardened steel and milling media was made of hardened chrome steel, 5 drops of methanol were used as a process control agent to avoid excessive cold-welding of the powder particles. Secondly, Al2024 alloy powders were milled with various weight fraction of as-milled $\mathrm{Ti} / \mathrm{B} 4 \mathrm{C}$ powders, the milling time was constant ( 2 hours). The detailed composition of each simple is shown in table 1 . The blended powders were consolidating by uniaxial compression a pressure of $900 \mathrm{MPa}$ and sintered for $1 \mathrm{~h}$ at $500{ }^{\circ} \mathrm{C}$.

Microstructure of $\mathrm{Al} 2024-\mathrm{Ti} / \mathrm{B} 4 \mathrm{C}$ bulk composites were examined by scanning electron microscopy (SEM) and energy dispersive spectroscopy (EDS) using Hitachi SU3500. Mechanical properties were characterized by compression test at room temperature. The values of yield strength, ultimate tensile strength and elongation were taken from an average of three samples.

Fig. 1 shows an X-ray diffraction (XRD) pattern of the sintered sample. It can be seen that the composite has four phases including $\mathrm{Al}, \mathrm{Ti}, \mathrm{AlTi} 3$ and $\mathrm{B} 4 \mathrm{C}$.

Fig. 2a shows an SEM image of the composite, showing that a lot of core-shell structured particles distribute uniformly in the aluminum alloy 2024 matrix. Fig. $2 b$ shows cross-section morphologies of the as-milled Ti/B4C particles and enlarged SEM image and the corresponding EDS analysis. It can be seen that the composite consists of four different phases, including aluminum alloy 2024 matrix, $\mathrm{B} 4 \mathrm{C}$ particles and white core and gray shell. The EDS results reveal that the dark matrix is pure Al, the white core is pure $\mathrm{Ti}$, and the gray shell is composed of $\mathrm{Al}$ and $\mathrm{Ti}$, indicating that the shell is in situ formed intermetallic compound AlTiz.

The results of compression stress-strain of the composites with various $\mathrm{Ti} / \mathrm{B} 4 \mathrm{C}$ content show a behavior where the yield strength and ultimate compression strength increased with the increase of $\mathrm{Ti} / \mathrm{B} 4 \mathrm{C}$ content, thinking that the core-shell structured $\mathrm{Ti} / \mathrm{B} 4 \mathrm{C}$ particles could effectively strengthen the aluminum alloy 2024 [4].

Table 1. Chemical composition of the bulk Al2024-Ti/B4C. 


\section{Chemical composition}

A12024

$\mathrm{Al} 2024-1.5 \% \mathrm{Ti} / \mathrm{B} 4 \mathrm{C}$

$\mathrm{A} 12024-2.0 \% \mathrm{Ti} / \mathrm{B} 4 \mathrm{C}$

Al2024-3.0\% Ti/B4C

$\mathrm{A} 12024-10.0 \% \mathrm{Ti} / \mathrm{B}_{4} \mathrm{C}$

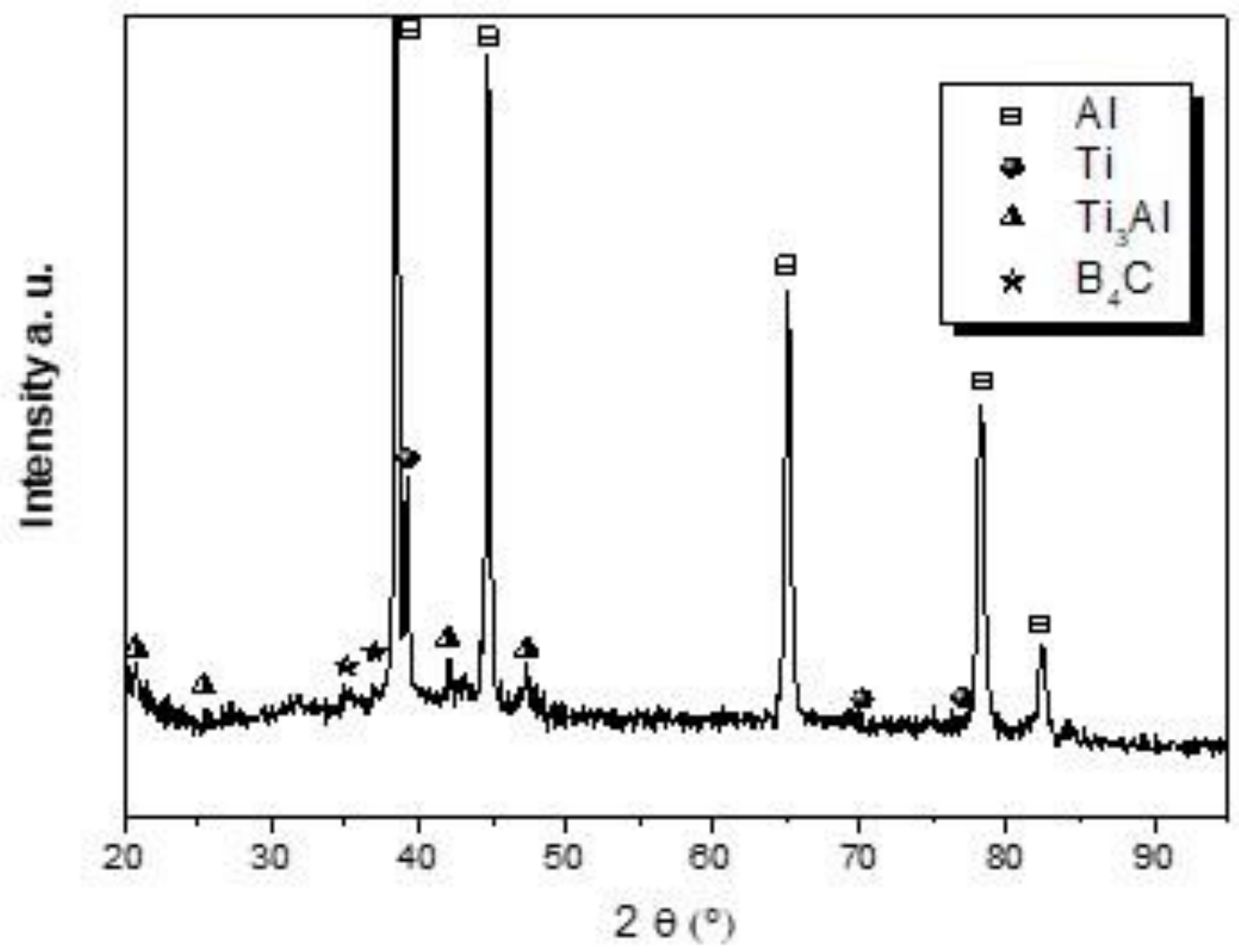

Figure 1. X-ray diffraction pattern of the composite. 


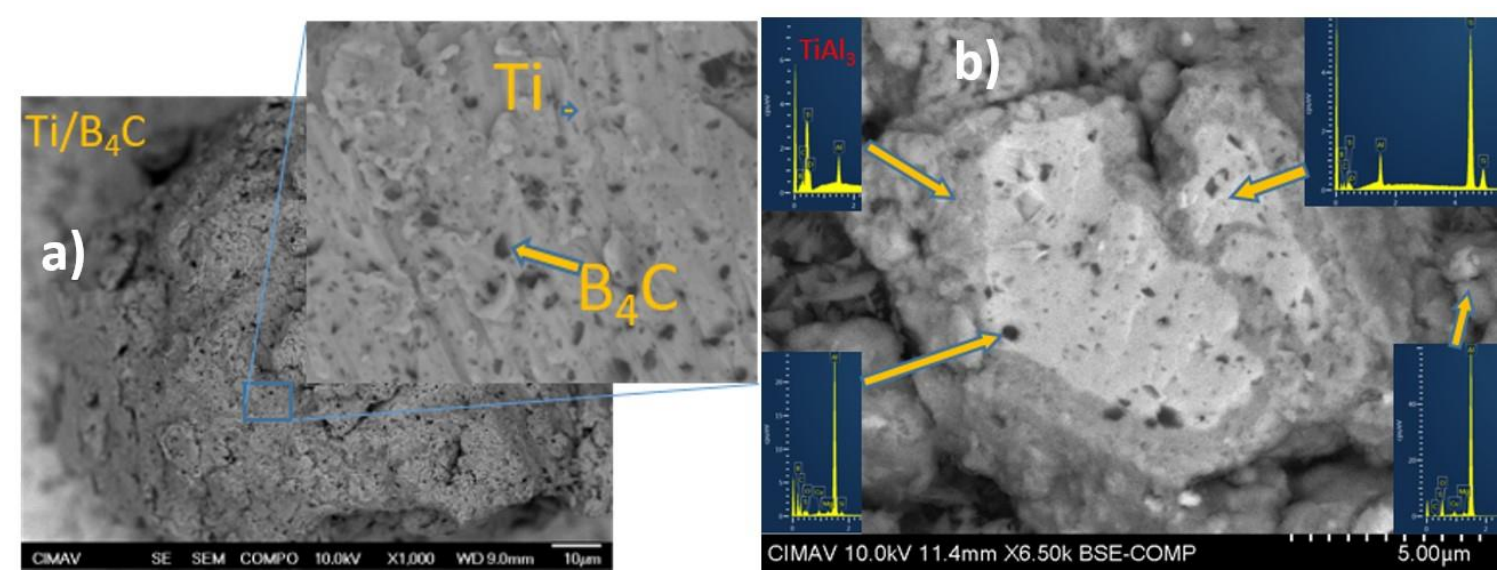

Figure 2. (a) shows cross-section morphologies of the as-milled Ti/B4C particles. The fine B4C particles are uniformly distributed within the coarse Ti powders after mechanical milling

\section{References}

1. K. Surappa, Sadhana - Acad. Proc.Eng.Sci.28(2003)319-334.

2. M. Torralba, C.E. da Costa, F. Velasco, J. Mater. Process. Technol. 133 (2003) 203-206.

3. Baisong Guo, Song Ni, Rujuan Shen, Min Song Materials Science and Engineering: A, 639, 2015, Pages 269-273.

4. The authors acknowledge to the Red Temática Nacional de Aeronáutica, Red Materiales Compuestos and Red Temática de Nanociencias y Nanotecnología (152992). 